\title{
Stimulus correlates of tachistoscopic discrimination-recognition performance: Compactness, jaggedness, and areal asymmetry ${ }^{1}$
}

\author{
G. ALFRED FORSYTH, ${ }^{2}$ UNIVERSITY OF NEW HAMPSHIRE \\ DONALO R. BROWN, PURDUE UNIVERSITY
}

The utility of three physical dimensions (compactness, jaggedness, and areal asymmetry) of four-sided random forms on discrimination-recognition performance was examined. Six experimental conditions were defined by constructing discrimination-recognition problems wherein forms were paired on the basis of a high or low value on each of the three physical dimensions. Twenty-six Ss were randomly assigned to each experimental condition and were tested on five problems, four times at each of five single form duration times. Each problem presentation consisted of selecting which of two forms had been previously exposed at the selected duration. Analyses of the number of correct responses indicated support for the existence of a selective attention process and the utility of the compactness physical dimension.

Gibson (1963) maintains that the senses are not only receivers and transducers of energy, but also assume a role in exploring, searching, and selecting environmental energy. This theory demands that attention is a process which starts at the periphery. In an attempt to define the processes of recognition, assimilation, and identification, Beach (1964) proposed a cognitive structure which was described as a multidimensional space defined by the cue dimensions or physical dimensions to which an Individual attends. Building upon this theoretical foundation, and attending primarily to logon variability (based on different dimensions) rather than metron variability (based on discriminable units along a single dimension; Attneave, 1959; Garner, 1962), the present authors suggest that there is an hierarchical order of physical dimensions to which an individual attends in the perceptual process. If it can be demonstrated that such a hierarchy exists, it should eventually be possible to attach weights to each physical dimension to indicate relative position in the hierarchical listing and to examine how various environmental variables alter the weights for different types of individuals with a variety of hierarchies or cognitive structures.

In a review of selective attention literature, Egeth (1967, p. 55) concluded that "one of the important tasks for future research is the exact specification of the coding responses which enable subjects to respond selectively to specified portions of complex stimuli." However, as Gibson (1951) indicated, the aspects of the study of perception concerned with how things are perceived can only be pursued when we know what is perceived. Within Gibson's theoretical framework, which posits that physical dimensions determine every perceptual response (Gibson \& Gibson, 1955), to know what is perceived demands a physics of stimuli.

The awareness of the need for a physical quantification of complex stimuli has long been apparent (Stevens, 1951, p. 32; Gibson, 1951), and the problems associated with such a program have been discussed within the context of form perception (Attneave \& Arnoult, 1956; Brown \& Owen, 1967; Michels \& Zusne, 1965). Brown and Owen (1967) have summarized one methodology and the results produced by it in their efforts to build a physics of visual form for a specific stimulus domain. This study is part of a program of research designed to explore the existence of a hierarchical order of physical dimensions of stimulation and variables which alter that hierarchy. Specifically, it evaluates the utility of three specific form characteristics in the solution of discrimination-recognition problems.

\section{Subjects}

\section{METHOo}

One hundred fifty-six undergraduate students, 42 male and 114 female, enrolled in introductory psychology at Purdue University served as Ss in this experiment in fulfillment of course requirements.

\section{Stimuli and Problems}

Stimuli were selected from a sample of 200 foursided forms generated from the stimulus domain suggested by Attneave and Arnoult's Method 1 (1956) and described in detail by Brown and Owen (1967). Forms were selected so that five problems could be constructed for each of six groups. Each problem consisted of two plctures, one a single form and the other that same form paired with another form.

The six groups of five problems were defined by the factorial combination of three stimulus dimensions with two types of form pairing. The single form was always selected to rank high on the selected dimension and was paired with a form also ranking high on the dimension $\left(R_{h h}\right)$ or with one ranking low on the dimension $\left(\mathrm{R}_{\mathrm{hl}}\right)$. The definition of a form as high or low in rank on a given dimension was based upon the rank ordering of factor scores 


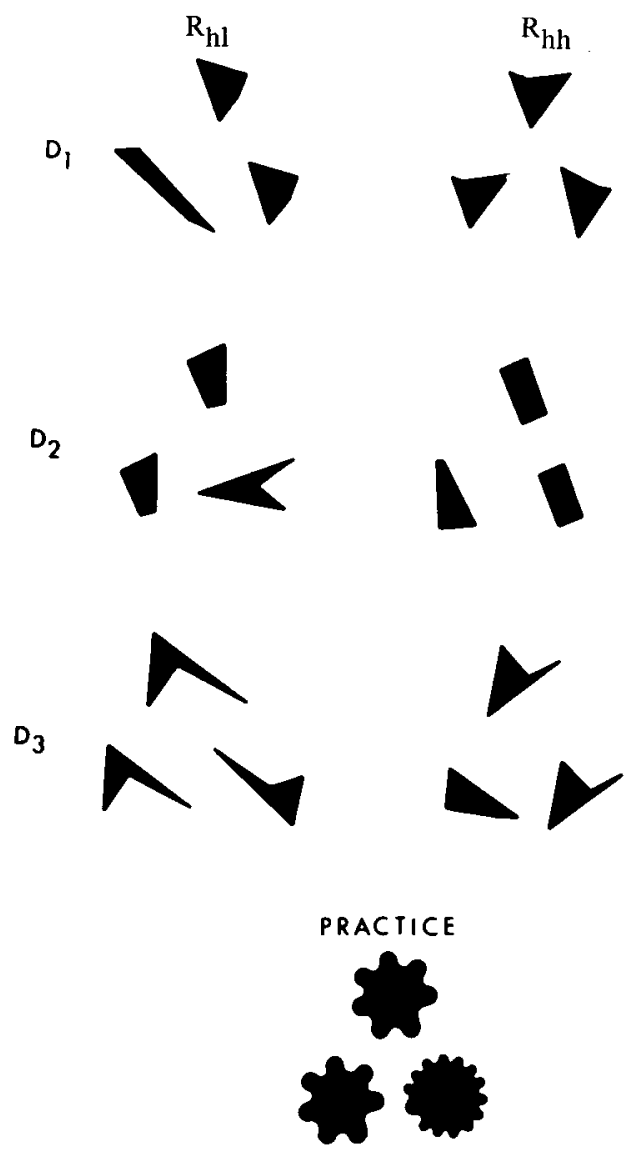

Fig. 1. Examples of discrimination-recognition pmblems used to define experimental groups.

of 200 forms on the physical dimension under consideration. The high and low ranking stimuli used in this study were selected from the forms with the highest and lowest 15 factor scores, respectively. The three stimulus dimensions studied were "compactness," "jaggedness," and "x-axis areal asymmetry." These dimensions have been described in detail by Brown and Owen (1967). The experimental design is represented by example problems in Fig. 1.

\section{Apparafus and Procedure}

The apparatus used to present the stimuli was a three-channel tachistoscope (Scientific Prototype, Model GB) and its programming unit. The first field was used to present the single form for from 4 to $20 \mathrm{msec}$ and the second field was used to provide a $300 \mathrm{msec}$ blank interval before two forms were presented in field 3 of the tachistoscope.

Following the presentation of tape recorded instructions, S was given eight practice trials with the tachistoscope using curvilinear forms (see Fig. 1). A single trial consisted of presenting a single form for a duration of $4,8,12,16$, or $20 \mathrm{msec}$, then a blank presentation for $300 \mathrm{msec}$, followed by a presentation of the same form presented in its problem pair. S's task was to respond with the side on which the previously shown form appeared. If $\mathrm{S}$ did not know which form had appeared alone, the answer "no" was to be given. Following the practice trials, $S$ was instructed that the testing session was to begin. Each $S$ was exposed to five problems, four times at each of the single-form duration times of $4,8,12,16$, or $20 \mathrm{msec}$ for a total of 100 trials. The order of presentation was randomized on the basis of problem and duration with the restriction that the same problem never succeeded itself.

Subjects were randomly assigned to the six groups defined by the factorial combination of the three stimulus dimensions with the two types of form pairing, with seven male and 19 female Ss in each group. Thus, the complete experimental design consisted of three factors varied at two, three, and five levels, respectively, with repeated measures on the five-level factor. The five-level, repeated measures factor was the exposure duration of the first form.

\section{RESULTS}

Table 1 presents the mean number of correct responses for each treatment condition. Results of an analysis of variance are summarized in Table 2. The significant Rank main effect $(p<.005)$ reflects higher mean performance (66.00) when intraproblem differences were present $\left(R_{h l}\right)$ as compared to problems in which such differences were absent $\left(R_{h h}\right)$ and mean performance was poorer $(58.30)$. The significant $(p<.005)$ Rank by Dimension interaction is shown in Fig. 2 and qualifies the Rank effect. A test of simple main effects on differences between the $\mathbf{R}_{h l}$ and $\mathbf{R}_{h h}$ groups for each dimension separately showed a significant effect only for compactness ( $p<.005)$.

As anticipated, the Time main effect was significant $(p<.0001)$. This variable was included in the design to obtain threshold values for each problem for future experiments. Both the Dimension by Time and the Rank by Time interactions were also significant $(p<.005)$. Figure 3 presents the Dimension by Time interaction, indicating that Dimension 1 received less benefit from longer exposure to the single form than

Table 1. Mean Number of Correct Responses

\begin{tabular}{|c|c|c|c|c|c|c|}
\hline & \multicolumn{5}{|c|}{ Time } \\
\hline & & 1 & 2 & 3 & 4 & 5 \\
\hline \multirow{2}{*}{$D_{1}$} & $R_{h l}$ & 5.23 & 13.81 & 16.96 & 17.50 & 18.08 \\
\hline & $R_{h h}$ & 2.77 & 7.85 & 10.81 & 11.42 & 11.96 \\
\hline \multirow{2}{*}{$D_{2}$} & $R_{h l}$ & 3.19 & 12.26 & 16.04 & 17.30 & 17.35 \\
\hline & $R_{h h}$ & 4.04 & 11.96 & 14.46 & 16.00 & 15.65 \\
\hline \multirow{2}{*}{$D_{3}$} & $R_{h l}$ & 1.81 & 10.65 & 15.00 & 16.15 & 16.58 \\
\hline & $R_{h h}$ & 3.00 & 13.81 & 16.46 & 17.77 & 17.15 \\
\hline
\end{tabular}


Table 2. Analysis of Variance for Number Correct

\begin{tabular}{lrrc} 
Source & df & M.S. & F \\
\hline Between Subjects & 155 & & \\
Dimension (D) & 2 & 120.90 & 2.50 \\
Rank (R) & 1 & 461.54 & $9.55^{*}$ \\
D X R & 2 & 808.15 & $16.72^{*}$ \\
Ss within groups & 150 & 48.33 & \\
Within Subjects & 624 & & \\
Time (T) & 4 & $4,530.92$ & $622.79^{*}$ \\
D X T & 8 & 34.60 & $4.75^{*}$ \\
R X T & 4 & 32.50 & $4.46 *$ \\
D X R X T & 8 & 13.84 & 1.90 \\
T X Ss within groups & 600 & 7.28 & \\
Total & 779 & & \\
\hline
\end{tabular}

* $F$ value significant at the .005 level.

either Dimensions 2 or 3 . Figure 4 presents the Rank by Time interaction, and indicates that increases in single-form presentation time facilitate performance for $\mathbf{R}_{\mathrm{hl}}$ problems more than for $\mathbf{R}_{\mathrm{hh}}$ problems.

\section{DISCUSSION}

The theoretical formulations of Gibson (1963) and Beach (1964), and the notion of a hierarchy of physical dimensions to which $\mathrm{S}$ attends presented in this paper would all have led to the same prediction; if any dimension examined in this study had been a dimension to which Ss attend, the group exposed to $\mathbf{R}_{\mathrm{hl}}$ problems would perform better than the group exposed to $R_{h h}$ problems. This was confirmed for the compactness dimension. It is somewhat surprising that the jaggedness dimension was not used for discrimination. This measure is physically defined by angle characteristics (Brown \& Owen, 1967) and previous research has demonstrated that such characteristics are predic- tive of judged complexity (Goldstein \& Andrews, 1962; Owen \& Brown, 1966). This discrepancy may have been a function of: (1) different dimensions attended to when Ss judge complexity than when making discrimination judgments, (2) different dimensions attended to when tachistiscopic versus longer stimulus examination periods are used, or (3) the error of grouping individuals, not all of whom attend to the same physical dimensions (Tucker \& Messick, 1963).

Finally, the results may in part be a function of sampling limitations associated with small form samples (Brown \& Owen, 1967). Examination of thresholds for each problem for this dimension showed a high threshold for one $R_{h l}$ problem and a low threshold for one $\mathbf{R}_{\text {hh }}$ problem. It was noted that the high threshold $\mathbf{R}_{\mathrm{hl}}$ problem was one in which the paired forms were equated on an extraneous "rotation" dimension (Brown \& Owen, 1967) while the low threshold $\mathbf{R}_{\mathrm{hh}}$ problem paired forms which were markedly disparate on that dimension. Subjects may have attended to the rotation dimension on those two problems obscuring differences associated with the dimension under study. No evidence was obtained to support the utility of the areal asymmetry dimension.

While no attempt was made to obtain a complete determination of the physical dimensions to which Ss attend, the data provide support for the utility of selected physical dimensions of patterned stimuli and thereby contribute to the development of a psychophysics of form perception. Moreover, they suggest that perception is selective, and that the existence of a cognitive structure, in the sense proposed by Beach (1964), may be applicable to the explication of the perception of multidimensional stimuli. The complete definition of an individual's cognitive structure

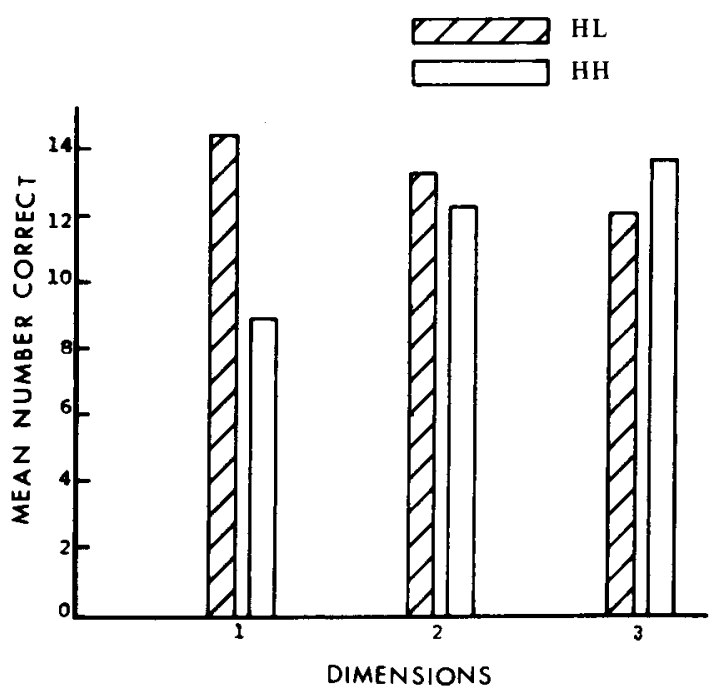

Fig. 2. Mean number correct per 20 trials plotted for each experimental group.

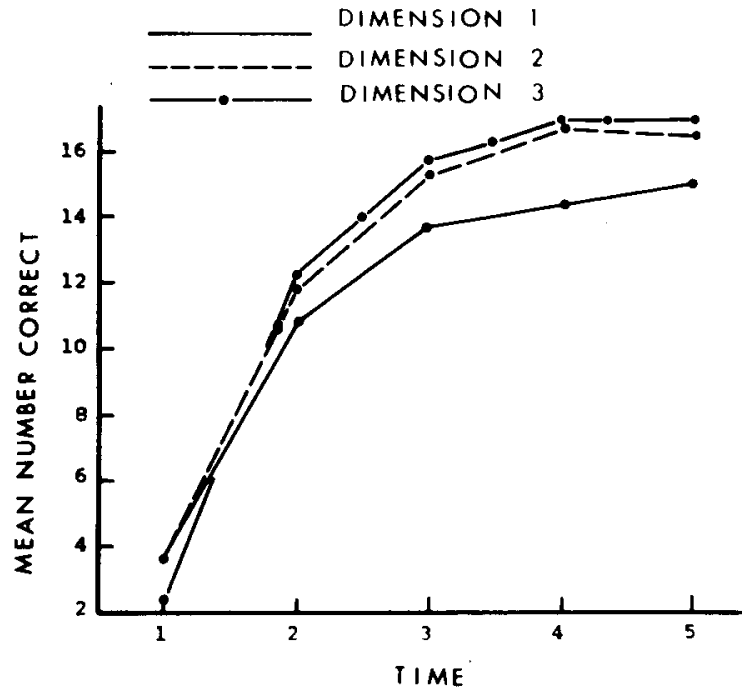

Fig. 3. Mean number correct plotted across presentation times for Dimension 1, 2, and 3 Groups. 


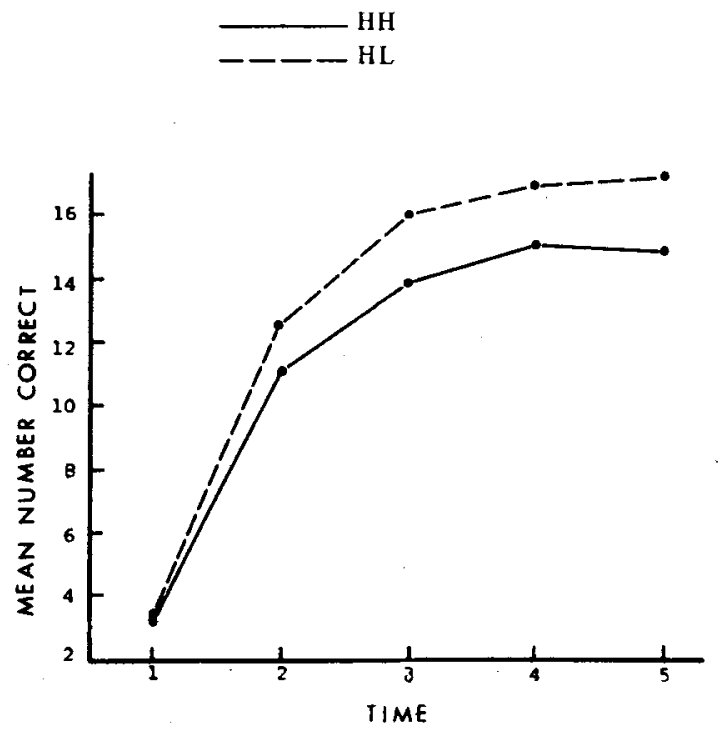

Fig. 4. Mean number correct plotted across presentation times for $R_{h h}$ and $R_{h l}$ problem groups.

and variables which alter it are problems for future research. It is Important to note that the physical dimensions determined to comprise a cognitive structure through the use of one stimulus domain are not necessarily generalizable to physical dimensions comprising cognitive structures of other domains. The nature of the stimulus domain may become an issue of major concern if the goal is to describe the cognitive structure for the stimulus domain of all real life objects, but is not crucial in the investigation of problems of selective attention or the study of variables hypothesized to alter an individual's cognitive structure.

\section{References}

Attneave, F. Applications of information theory to psychology: a summary of basic concepts, methods, and results. New York: Holt-Dryden, 1959 .

Attneave, F., \& Amoult, M. D. The quantitative study of shape and pattern perception. $P$ sychol. Bull., 1956, 53, 452-471.

Beach, L. R. Recognition, assimilation, and identification of objects. Psychol. Monogr., 1964, 78, No. 583.

Brown, D. R., \& Owen, D. H. The metrics of visual form: methodological dyspepsia. Psychol. Bull., 1967, 68, 243-259.

Egeth, H. Selective attention. Psychol. Bull., 1967, 67, 41-57.

Gamer, W. R. Uncertainty and structure as psychological concepts. New York: John Wiley \& Sons, Inc., 1962.

Gibson, J. J. What is form? Psychol. Rev., 1951, 58, 403-412. Gibson, J. J. The useful dimensions of sensitivity. Amer, Psychol. $1963,18,1-15$.

Gibson. J. J., \& Gibson, E. J. Perceptual learning: differentiation of enrichment? Psychol. Rev., 1955, 62, 32-41.

Goldstein, A. G., \& Andrews, J. Perceptual uprightness and complexity of random shapes. Amer. J. Psychol., 1962, 75, 667-669.

Michels, K. M., \& Zusne, L. Metrics of visual form. Psych. Bull., $1965,63,74-86$.

Owen, D. H., \& Brown, D. R. Physical correlates of pattern perception for the visual and tactual modalities. Paper read at Amer. Psychol. Assoc., New York, September, 1966.

Stevens, S. S. Mathematics, measurement, and psychophysics. In S. S. Stevens (Ed.), Handbook of experimental psychology. New York: John Wiley and Sons, Inc., 1951. Pp. 1-49.

Tucker, L. R., \& Messick, S. An individual differences model for multidimensional scaling. Psychometrika, 1963, 28, 333-367.

\section{Hotes}

1. This research was supported by Research Grant HD-00909 from the National Institute of Child Health and Human Development.

2. Adapted from a thesis submitted by the first author in partial fulfillment of the requirements for the Ph.D. degree at Purdue University.

(Accepted for publication August 15, 1967.) 